\title{
On the relation between the crude oil market and pandemic Covid-19
}

\author{
Imlak Shaikh \\ Management Development Institute Gurgaon, Gurugram, India
}

\begin{abstract}
Purpose - The crude oil market has experienced an unprecedented overreaction in the first half of the pandemic year 2020. This study aims to show the performance of the global crude oil market amid Covid-19 and spillover relations with other asset classes.

Design/methodology/approach - The authors employ various pandemic outbreak indicators to show the overreaction of the crude oil market due to Covid-19 infection. The analysis also presents market connectedness and spillover relations between the crude oil market and other asset classes.

Findings - One of the essential findings the authors report is that the crude oil market remains more responsive to pandemic fake news. The shock of the global pandemic panic index and pandemic sentiment index appears to be more promising. It has also been noticed that the energy trader's sentiment (OVX and OIV) was measured at a too high level within the Covid-19 outbreak. Volatility spillover analysis shows that crude oil and other market are closely connected, and the total connectedness index directs on average $35 \%$ contribution from spillover. During the initial growth of the infection, other macroeconomic and political events remained to favor the market. The second phase amidst the pandemic outbreak harms the global crude oil market. The authors find that infectious diseases increase investor panic and anxiety.

Practical implications - The crude oil investors' sentiment index OVX indicates fear and panic due to infectious diseases and lack of hedge funds to protect energy investments. The unparalleled overreaction of the investors gauged in OVX indicates market participants have paid an excessive put option (protection) premium over the contagious outbreak of the infectious disease.

Originality/value - The empirical model and result reported amid Covid-19 are novel in terms of employing a news-based index of the pandemic, which are based on the content analysis and text search using natural processing language with the aid of computer algorithms.
\end{abstract}

Keywords Covid-19, Crude oil, Investors' sentiment, Pandemic, OVX, VIX

Paper type Research paper

\section{Introduction}

The crude oil market has experienced an unprecedented overreaction in the first half of the pandemic year 2020, and the dynamic of the global crude oil has significantly transformed over the past decade. The inventions of alternative energy resources, discoveries and exploitation have controlled a large volume of new oil fields and further emergence of carbon substitute energies worldwide. Consequently, since the past one-decade energy market is no longer demand-driven, the market turned into supply-driven. Following the recent tail events, crude oil is struggling and finding the best global price. The pandemic outbreak Covid-19 has disrupted the global supply chain, and the contraction of the energy demand has caused

\section{JEL Classification - C32, I10, Q02}

(C) Imlak Shaikh. Published in European Journal of Management and Business Economics. Published by Emerald Publishing Limited. This article is published under the Creative Commons Attribution (CC BY 4.0) licence. Anyone may reproduce, distribute, translate and create derivative works of this article (for both commercial and non-commercial purposes), subject to full attribution to the original publication and authors. The full terms of this licence may be seen at http://creativecommons.org/licences/by/4.0/ legalcode

The authors want to thank Editor-in-Chief Prof. Enrique Bigné and Associate Editor Txomin Iturralde for the swift editorial proceeding and feedback. Also, the authors thank two anonymous referees for their valuable suggestions and comments. The authors sincerely thank RavenPack (https:// coronavirus.ravenpack.com/) for the data access on text analytics-based coronavirus indexes.

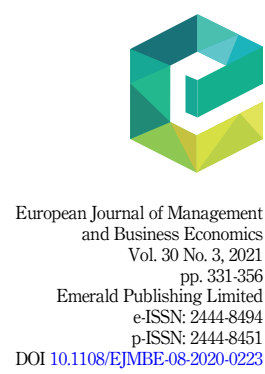

Received 13 August 2020 Revised 28 November 2020 Accepted 23 December 2020 
EJMBE 30,3

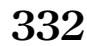

global crude oil to fall historically low. Hence, the study aims to demonstrate oil price dynamics amid Covid-19 and spillover relations with other asset classes. We examine the oil prices responses to the pandemic shock measured in terms of various pandemic indices. For example, world coronavirus pandemic panic index (WCPI), world coronavirus media hype index (WCMHI), world coronavirus fake news index (WCFNI) and global pandemic-led sentiment index. Moreover, we show how crude oil prices react to the infectious pandemic diseases outbreak based on the Infectious Diseases Equity Market Volatility tracker (IDEMV-COVID-19).

The novel coronavirus - which the Chinese administration first reported to the World Health Organization (WHO) on December 31, 2019, has exploded internationally. Moreover, the WHO announced novel coronavirus as a public health emergency on January 30, 2020, and on March 11, 2020, declared novel coronavirus (i.e. COVID-19) as a global pandemic outbreak. The virus has infected more than 14,439,253 people and caused about 605,110 deaths as of July 19, 2020 [1]. More than 8,564,108 individuals have recovered. Arezki and Nguyen (2020) examine pandemic shock to the oil prices in the major oil-producing countries. The authors emphasize two types of shock: administration should order and tailor their responses and concentrate on reacting to the health emergency and the accompanying risk of economic depression. Further, the authors depict negative supply and demand shock on global crude oil prices. The interruption in negotiations amid the Organization of the Petroleum Exporting Countries (OPEC) and its partners led to what will likely be a tenacious downfall in oil prices (Norouzi and Fani, 2020). Jhawar and Gopalakrishnan (2020) express their concern about the novel Covid-19 infectious disease and deteriorating economic activity, leading to an energy demand crisis. The oil sector has been particularly hit by the global financial crisis (GFC) 2008 , and the worst price of crude traded historically below zero.

Brent oil prices have collapsed around $60 \%$ since the start of the year 2020, while US crude futures (WTI) have fallen around $130 \%$ to levels well below (-US\$37/b); this has led to drilling breaks and extreme expenditure cuts. Pellejero (2020) analyze the future status of the global crude oil and find that rising US crude oil inventories could hinder the retrieval in oil prices by 2021. Further, there is a concern about fuel consumption likely to remain tepid because of infectious coronavirus apprehensions. Hence, our research questions are threefold: (1) What contains the pandemic outbreak news to explain the oil market? (2) Are the oil market and other assets connected during the pandemic outbreak? (3) Does OVX measure the fear of the energy traders during the outbreak of pandemic? We employ various pandemic outbreak indicators to show the overreaction of the crude oil market due to Covid-19 infection. One of the essential findings we report is that the crude oil market remains more responsive to the pandemic fake news. Second, the global pandemic panic index and pandemic sentiment index's shock appear to be more promising. It has also been noticed that the energy trader's sentiment (OVX and OIV) was measured at an extremely high level within the Covid-19 outbreak. The crude oil investors' sentiment index OVX indicates fear and panic due to infectious diseases and lack of hedge funds to protect the energy investments. Volatility spillover analysis shows that the crude oil and other market are closely connected, and the total connectedness index (TCI) directs on average 35\% contribution that comes from spillover.

Our study on the relationship between pandemic infection and news outbreak organized as Section 1 provides some exploratory observations about crude oil prices during the Covid-19 outbreak, Section 2 provides relevant recent literature evidence. Section 3 discusses the data sources and descriptions, along with preliminary statistical analysis. Section 4 explains the methodology and hypothesis development. Section 5 offers results and discussion, Section 6 presents robustness check and Section 7 ends with the conclusion. 


\section{Literature review}

Some of the early studies in relation to pandemic infections and financial market performance include: Chen et al. (2007) find due to severe acute respiratory syndrome (SARS), Taiwan's hospitality stock fell by about $29 \%$. Chen et al. (2009) report that SARS positively impacted the pharmaceutical and biotechnology stock on the Taiwan stock exchange. Further, Wang et al. (2013) extend work in terms of effects of pandemics such as Enterovirus 71, dengue fever, SARS and H1N1 on the biotechnology firms in Taiwan to uncover the impact on operational efficiency.

Studies on the pandemic and cognitive behavior (e.g. Lucey and Dowling, 2005; Cen and Yang, 2013; Baker and Wurgle, 2007) observe the influence of tail events on the investor's psychology and overconfidence, investors' biases, mood swings and anxiety on the market returns and volatility.

Numerous studies (e.g. Kamstra et al., 2003; Kaplanski and Levy, 2012; Cen and Yang, 2013) find that sunshine, public holidays and investors' nervousness and attitude swings affect the returns and asset pricing. Furthermore, an additional constituent of tail event studies (e.g. Yuen and Lee, 2003; Kaplanski and Levy, 2010; Donadelli et al., 2017) enlighten that unforeseen and natural events impact investors' sentiments; subsequently, it marks the risk-taking behavior and distress for trading and lowers the willingness to participate in a risky investment. On the other hand, disease outbreaks show a favorable outcome for pharmaceutical stocks. Henceforth, our study deliberates on pandemic information content explaining the energy market investors' sentiment, gauged in OVX and OIV.

Literature is booming to examine the effects of Covid-19 across various asset classes, e.g. currency market and exchange rates, equity market and cryptocurrency, global trade and carbon-constrained world. Salisu and Sikiru (2020) examine the effects of pandemic on the Asia-pacific Islamic stocks for the period August 2010 to September 2020 and find that Islamic stocks hold better hedging potential on the counterpart of conventional stocks during the pandemics and epidemics. Similarly, Gil-Alana and Claudio-Quiroga (2020) analyze the impact of Covid-19 on the Asian equity markets (KOSPI, Nikkei225 and Shanghai CSI300) to uncover permanent and transitory effects and report mean reversion for the Nikkei, while KOSPI and CSI are not, hence shocks are permanent. Further, He et al. (2020) explore the impact of Covid-19 on the Chinese stock market across various industries based on the event study approach and find an asymmetric impact on the industry, e.g. hard impact on the transportation, mining and energy, while health, education and information technology appear to be resilient. Studies reviewed herewith are based on the empirical convention that unexpected news, market overreact and a better understanding of the news among market participant results in market correction (Phan and Narayan, 2020).

On the other hand, studies, e.g. Paule-Vianez et al. (2020) and Chen et al. (2020), examine bitcoin price dynamics and find that during the uncertainty, bitcoin acts as a safe-haven asset, but through this pandemic, bitcoin has lost the title of a safe haven. Besides, there have been some recent studies (e.g. Bolaño-Ortiz et al., 2020; Vidya and Prapheesh, 2020; Sovacool et al., 2020) that present their concern about the likely impact of Covid-19 on atmospheric emission, disruption in the global trade networks and sustainability transitions in a carbonconstrained world. Further, Haldar and Sethi (2020) explain the importance of government intervention amid Covid-19, referring to ten counties' socio-economic indicators and report that demographic factors and government policies help in reducing the growth of pandemic infection. Unlike previous studies, e.g. Narayan (2020a, b) studies the effects of Covid-19 on the exchange rate and bubble activity for the major global currencies and find that the pandemic has changed the resistance of the yen to shocks and bubble activity detected for the major four exchange rates (Japanese yen, euro, British pound and Canadian dollar) during the Covid-19 infection period.
The pandemic and oil market 
EJMBE 30,3
Bakas and Triantafyllou (2020) investigate the effects of pandemic uncertainty on commodity index and show a substantial adverse impact on the commodity market's volatility and also reveal that crude oil market experiences worst effects, while gold remain resilient. Likewise, Ali et al. (2020) examine the pandemic impact on the financial market and find that the global spread of novel coronavirus has first disrupted the European market and later the USA and even safer commodities. Further, Goodell (2020) highlights some of the contemporary issues amid Covid-19 in the finance discipline and studies positioning the likely impact of the large-scale event, epidemic and pandemics and their economic consequences, direct and indirect effects on the financial markets and institutions.

Haroon and Rizvi (2020) analyze the effects of media coverage of pandemic Covid-19 on equity markets and find that there has been an overwhelming panic caused by the news platforms that are associated with the rising volatility in the stock markets. More recently, AlAwadhi et al. (2020) investigate the impact of an infectious disease outbreak on the Chinese stock market. Their model setting is in panel data. They find that daily Covid-19 cases and fatality influence the stock returns adversely, and it is true across all firms. Also, Zhang et al. (2020) examine the global impact of the pandemic Covid-19 on the global financial markets; the authors measure the effects of such pandemic in terms of country-specific risks, a systematic risk. They show that pandemic infections have created an unprecedented level of financial risk with a short horizon.

There have been many recent attempts that deal with the potential impact of Covid-19 on energy trading, diesel consumption, OPEC oil production and electricity demand. Salisu and Adediran (2020) examine the effects of uncertainty due to infectious diseases measured in terms of equity market volatility infectious diseases index (ID-EMV); their in-sample and out-of-sample analysis reveal that ID-EMV is a good predictor of the energy market volatility. Further, Polemis and Soursou (2020) examine Greek energy firms amid the Covid19 pandemic based on the event study approach in a window of ten days before and after the lockdown and find that pandemic infection affected the returns of the majority of the energy firms adversely. Similarly, Ertuğrul et al. (2020) analyze the Turkish diesel consumption volatility dynamics amidst a pandemic outbreak and find that volatility remained higher during mid-April 2020 and reached the extreme level on May 24, 2020. The authors suggest that rearrangement of profit margin and tax exemption compensate for lost tax benefit. Also, Norouzia et al. (2020) study the impact of pandemic infection on the Chinese market's oil and electricity demand; their environmental analysis shows that Covid-19 impacted the fuel demand and electricity significantly. The elasticity of oil and electricity remain inverse, based on the number of people infected. Likewise, Qin et al. (2020) exhibit the essential role of Covid-19 on the oil market and show that oil demand is adversely associated with pandemic and causing a decrease in the oil prices based on the capital asset pricing model (CAPM) using the pandemic index (PDI). Further, Devpura and Narayan (2020) examine hourly oil price volatility considering Covid-19 infections. The important finding of the study is that number of Covid-19 cases and deaths increase oil price volatility ranging from 8 to $22 \%$.

Recent work relating to Covid-19 and the global crude oil market (e.g. Narayan, 2020; GilAlana and Monge, 2020; Liu et al., 2020; Apergis and Apergis, 2020) studies pandemic contagions and oil price news and political polarization, pandemic and volatility persistence and find that pandemic manifestation has dislocated the global crude oil prices and heightened in increased volatility and oil price battles. Hence, unlike the initial scholarly attempts, our study contributes to media coverage-based pandemic indices and the effects of such an outbreak of infection on the global crude oil prices. Moreover, our empirical work encompasses dynamic spillover and market connectedness among major asset classes, including crude oil. 


\section{Data sources, description and preliminary analysis}

The pandemic disease Covid-19 and global crude oil market relation hold importance for the energy traders and policymakers. Hence, in this study, we consider the effects of the recent pandemic outbreak on global crude oil prices. Our study samples the daily prices of energy commodity, stock index, gold futures and US dollar index from January 2, 2018 to June 30, 2020. In the pandemic infection studies, the Covid-19 outbreak period ranges from January 1 , 2020 to June 30, 2020. We explore the futures prices of the global crude oil in near terms, namely, West Texas Intermediate (WTI) and Brent. The crude oil WTI is US-based, while Brent acts as a global benchmark for crude oil and represents the OPEC partner countries. Also, we consider daily prices of Dow Jones Commodity Index (DJCI), SPX and Dow Jones Industrial Average (DJIA) equity index, gold futures (CME) and Dow Jones US dollar index (USDOLLAR). The dollar sneaked higher as concerns about the rise in new Covid-19 infections across the USA and other countries and emerging markets took the edge off the more massive market rally in recent months. Hence, we incorporate the US dollar index to control the global crude oil price in our empirical model.

Besides, our study takes into account the crude oil market sentiment index popularly known as OVX and OIV. OVX is the implied volatility index based on the options written on the United States Oil (USO) exchange-traded funds, and OIV represents the future market volatility of WTI futures-based options. OVX and OIV are the crude oil traders' fear and panic index expressed in percentage terms and available on a real-time basis. To examine the effects of the Covid-19 outbreak on the crude oil market, we consider the diseases and pandemic outbreak indices, e.g. WCPI, WCMHI, WCFNI and world coronavirus sentiment index (WCSENI) [2]. Moreover, we employ Baker et al. (2019, 2020a, b) pandemic infectious disease outbreak market tracker separated from equity market volatility (EMV) tracker know as Infectious Disease Equity Market Volatility tracker (ID-EMV) [3]. All the above-mentioned pandemic indices are calculated based on text mining and content analysis by referring to websites and leading newspapers. Hence, we aim to explore the effects of Covid-19 infection on the global crude oil prices by considering the pandemic indices and investor's fear and nervousness indices.

Figure 1 exhibits the temporal plot of the various pandemic indices constructed based on the natural language processing (NLP) architecture during the period of the Covid-19 outbreak. WCPI is the worldwide coronavirus pandemic index that ranges between 0 and 100 [4]. One can see that there has been a spike in the panic and Covid-19 news during March and April, and then it declines gradually and again, captivating a jump during June 2020. WCMHI is the worldwide coronavirus media hype index, which also falls between 0 and 100 [5], and it is apparent that the Covid-19 media hype was on the extreme level during March 2020 still. It ranges between 30 and $60 \%$. Next, WCFNI is the worldwide coronavirus fake news index measured between 0 and 100 [6]; it is visible that the fake news index amidst Covid-19 spiked during the March-April period. Further, WCSENI is the worldwide coronavirus sentiment index scaled from -100 and 100 [7]. We can see that the index falls below zero through the entire pandemic session and improves marginally by the end of June 2020. The last figure is the infectious diseases market volatility tracker based on major newspaper archives reporting news about the pandemic and contagious diseases. Higher values indicate greater pandemic coverage in print and online media, which interests the public (Haroon and Rizvi, 2020).

WCPI = world coronavirus pandemic panic index; $\mathrm{WCMHI}=$ world coronavirus media hype index; WCFNI = world coronavirus fake news index; WCSENI = world coronavirus sentiment index; ID_EMV = infectious disease equity market volatility tracker

Table 1 shows the descriptive measures in relation to the various indicators of the Covid-19 pandemic outbreak. The average reading of the global pandemic panic index was found to be $3.02 \%$, with a maximum value of $9.24 \%$ and a minimum of 0 . The mean level of
The pandemic and oil market 
EJMBE 30,3

\section{6}

Figure 1.

Covid-19-related PDIs
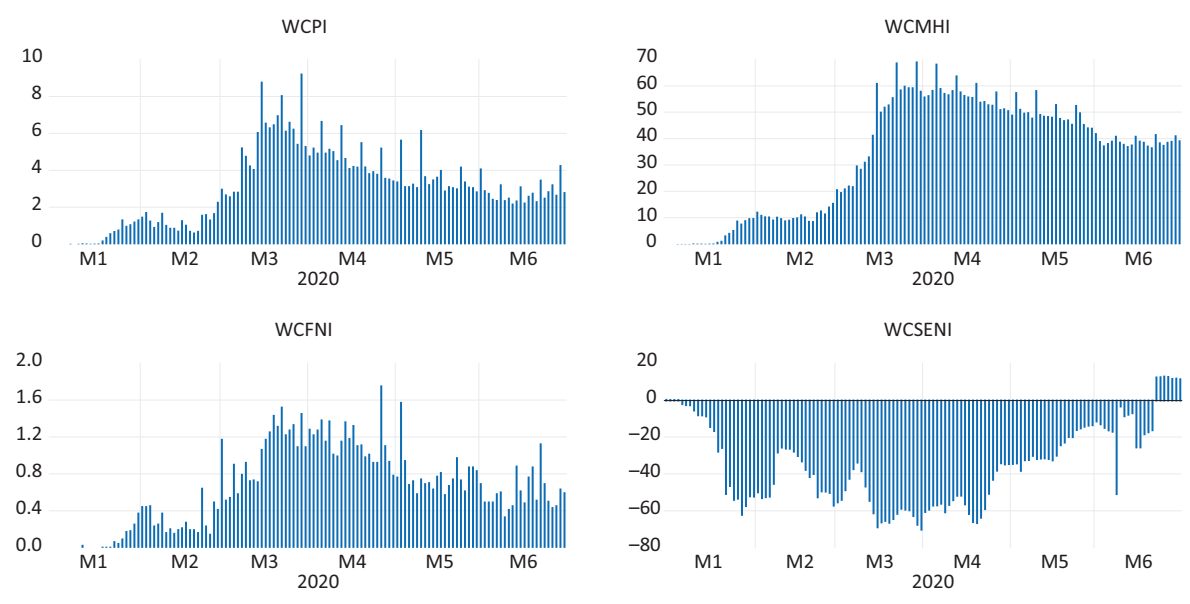

ID_EMV

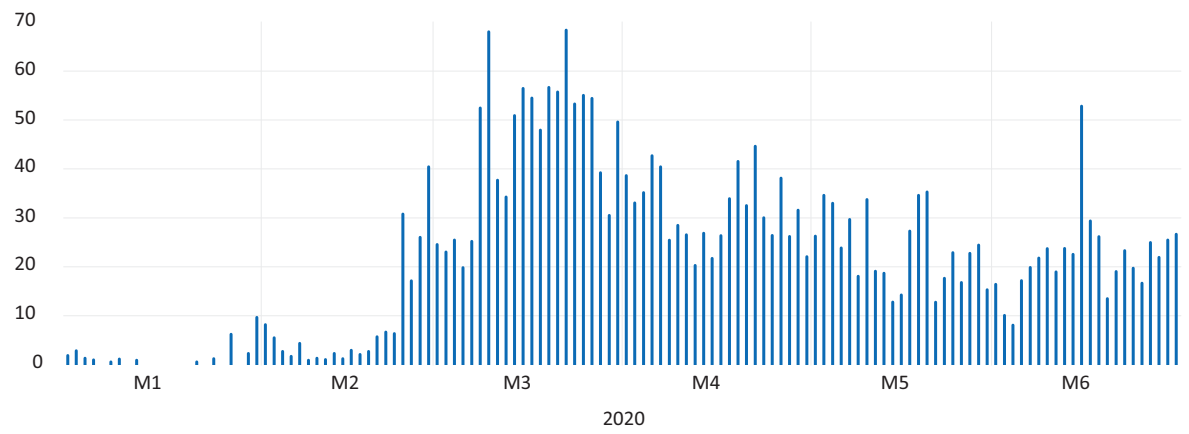

2020

\begin{tabular}{lcccrr}
\hline & WCPI & WCMHI & WCFNI & WCSENI & ID_EMV \\
\hline Mean & 3.0254 & 33.8379 & 0.6593 & -34.2309 & 21.9336 \\
Maximum & 9.2400 & 69.2700 & 1.7600 & 12.9800 & 68.3700 \\
Minimum & 0.0000 & 0.0000 & 0.0000 & -70.0000 & 0.0000 \\
Std. dev & 2.0616 & 21.5515 & 0.4433 & 22.6354 & 17.1277 \\
Observations & 130 & 130 & 130 & 130 & 130 \\
\hline
\end{tabular}

media hype was $33.83 \%$ along with a maximum point of $69.27 \%$ and a minimum level of 0 . Here, zero indicates there is no media coverage of the pandemic outbreak, and it appears zero in initial days of pandemic infection. The average measure of fake news index is $0.66 \%$, with maximum coverage of fake news $1.76 \%$. The global sentiment amid pandemic appears -34.23 with a maximum value of 12.98 , but the minimum level was -70.00 . The infectious diseases market volatility tracker was found to be an average of 21.96 points during the pandemic period, with a peak value of 68.37. We can see that the WCSENI appears with a more significant amount of variability, second WCMHI, and third ID_EMV.

Figure 2 displays the time-series plot of pairs of the WTI and Brent crude oil prices and pandemic outbreak. Now, one can see that WTI and Brent show similar patterns, but WTI is 

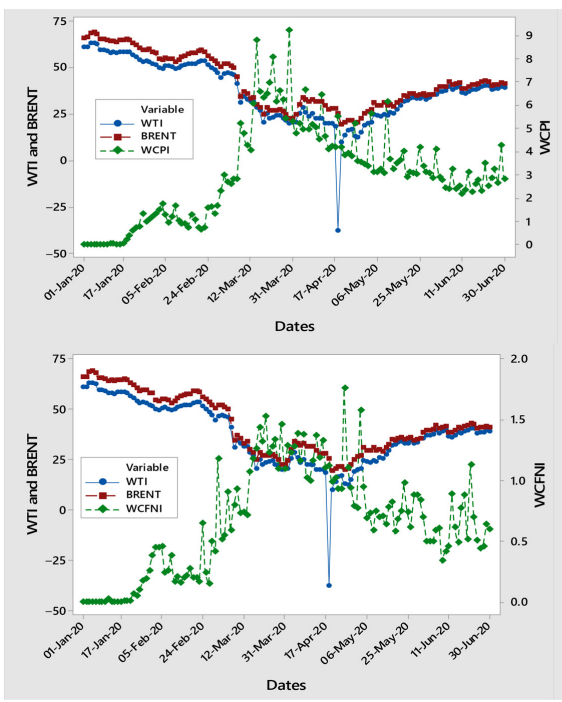
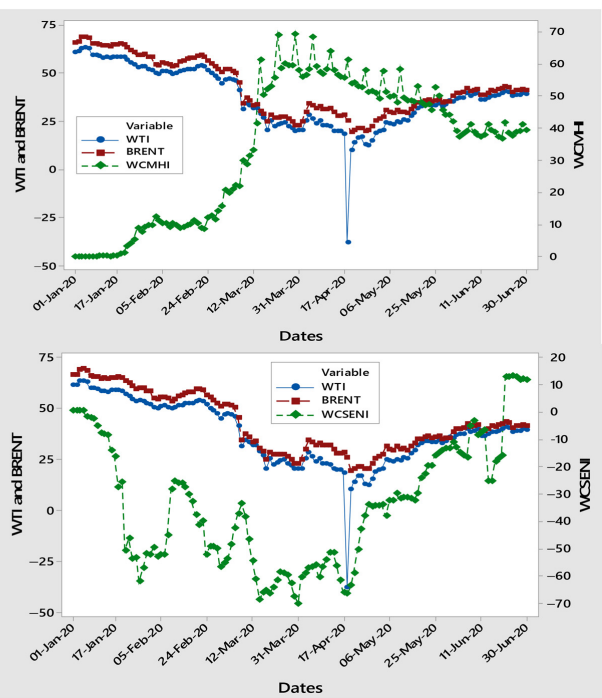

The pandemic and oil market

337

Figure 2.

WTI and Brent prices and Covid-19 pandemic outbreak

somehow more responsive to the pandemic infection with less than zero value. All four figures exhibit that crude oil prices and pandemic infection are adversely associated. The price of the WTI went negative first time in history amid the Covid-19 outbreak, measured at the peak level in terms of WCPI, WCMHI, WCFNI and shallow global sentiment. Figure 3 further expresses the same story. Global crude prices remain more volatile and start falling from US\$60 to minus US\$37 due to Covid-19 infections, which has resulted in the worldwide suspension of air travel, nationwide lockdown and social distancing. ID_EMV gauges the

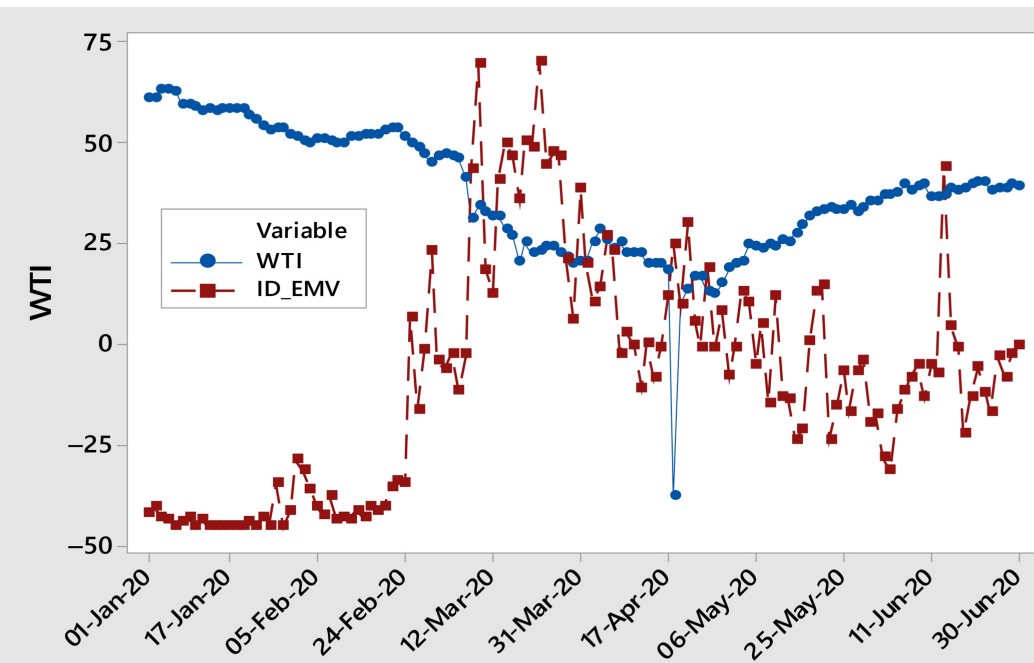

Dates

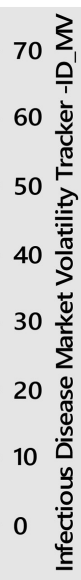

Figure 3.

WTI prices and infectious disease EMV tracker 
EJMBE 30,3

\section{8}

Covid-19 pandemic-associated movement (e.g. Salisu and Adediran, 2020), and we can see that infectious disease has adversely impacted the global crude oil market. Yet, WTI is searching for its best international price.

Table 2 demonstrates the various commodities and stock market indexes' prices and returns during the pandemic period. The mean level and returns (shown in parenthesis) of WTI and Brent were found to be $37.15(0.88 \%)$ and 42.21 (-5.77), with maximum (minimum) level 83.27 (-37.63) and 68.9 (19.33). The statistics summary indicates that WTI yielded positive returns but experienced negative price and stood more volatile during the infection period. The DJCI also returns negative $-2.94 \%$, with stable returns volatility. The other asset class DJIA yield negative returns $-1.23 \%$, with maximum (min) level of 29,551.42 (18,591.93). But one can see that gold and US dollar appear to be more promising, with positive mean returns, respectively, 2.04 and 0.15\% (Bakas and Triantafyllou, 2020). The US dollar continued strongly in recent years because the USA seemed to have an abundant robust economy, but the recent rise of the Covid-19 cases has hurt the currency. Hence, USD connected investors seeing healthier economic prospects in Europe and Asia that have controlled the pandemic more efficiently.

Figure 4 shows the relationship between expected crude oil market volatility (OVX) and global crude oil price. We can see that OVX - the investor's fear index - was below $50 \%$ up to February, but from March, it jumped amid Covid-19 news, and during April, it was plus $300 \%$. During March-April 2020, the OVX reading was too high, with a historically low price of WTI. Figure 5 further deliberates on the relation between the gold price and global crude oil. Gold is the global safe-haven commodity, and risk-averse market participants prefer gold investment more during the financial crisis (Bakas and Triantafyllou, 2020). We can see that through the entire pandemic period, gold spiked. During January 2020, it was about in a range of US $\$ 1,500-\mathrm{US} \$ 1,600$, but later, it was traded between US $\$ 1,700$ and US $\$ 1,800$. One can see that crude oil and gold price are inversely associated; it implies that due to an economic slowdown and pandemic outbreak, crude oil was low at all times, but gold was acting as a safe-haven traded at high volume price. Also, Figure 6 demonstrates the association between the US dollar index and crude oil prices. During the pandemic's peak, the US dollar index measured 12,900 plus, and WTI and Brent prices were below US $\$ 25$. It indicates that the global benchmark price of crude oil in terms of USD holds significance, a significant rise in the US dollar index causes decline in the oil price. But, we can see that the post-April 2020, the US dollar index goes down exponentially, and crude price gained their previous normal level.

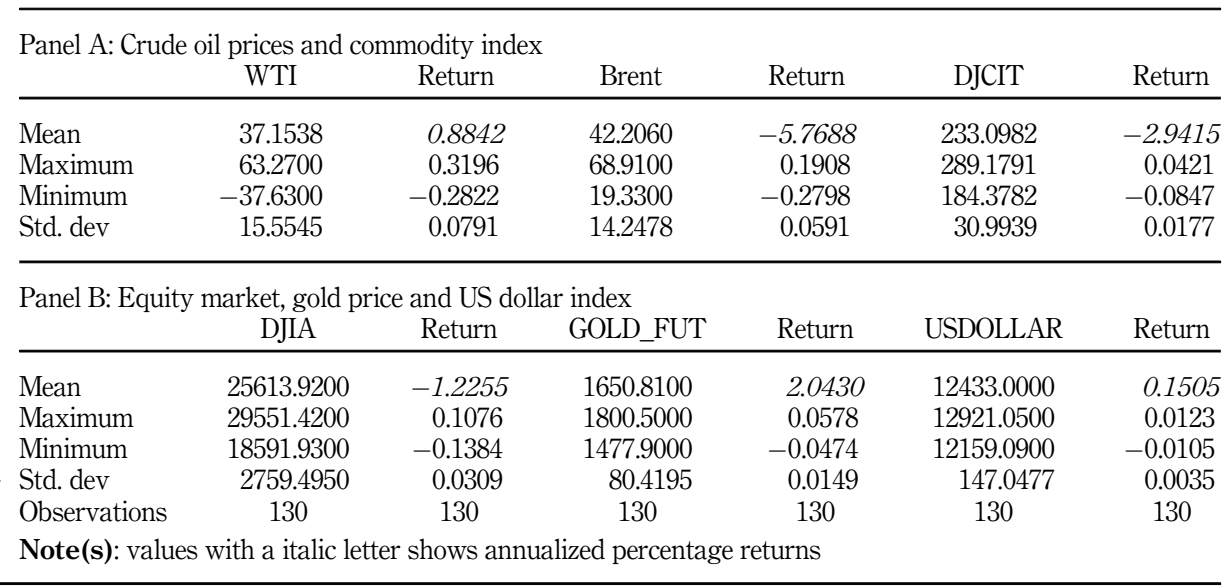

Table 2.

Descriptive statistics of crude oil prices and other assets 


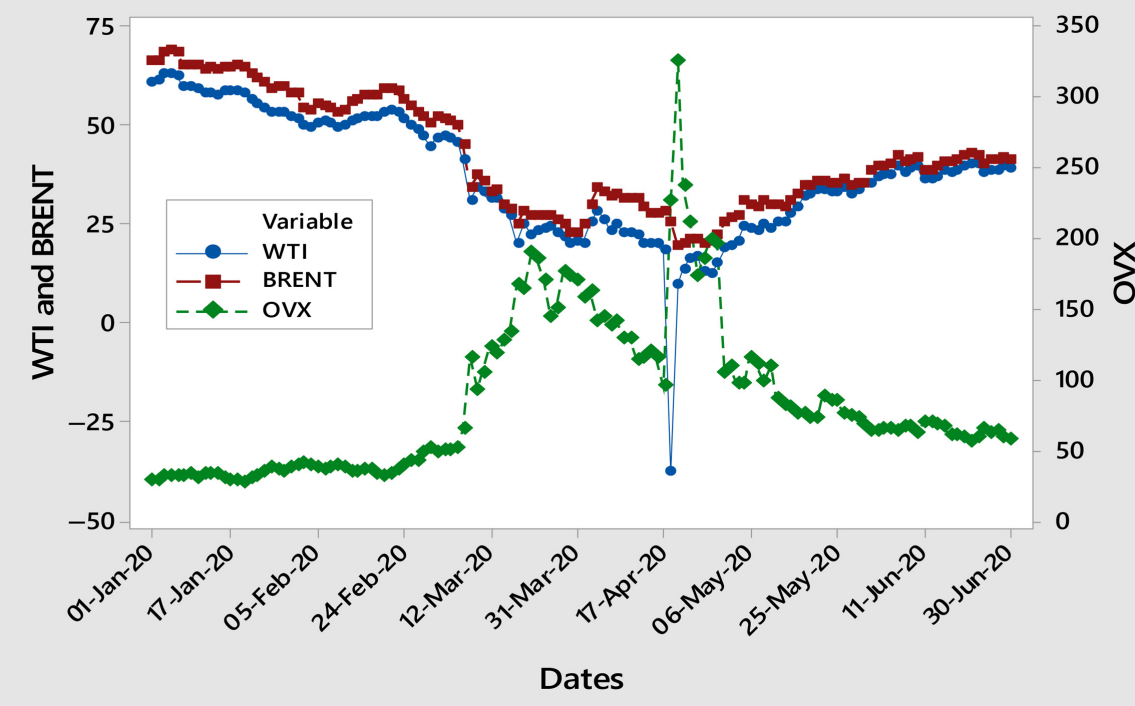

The pandemic and oil market

339

Figure 4.

On the relation

between oil market volatility and crude oil prices

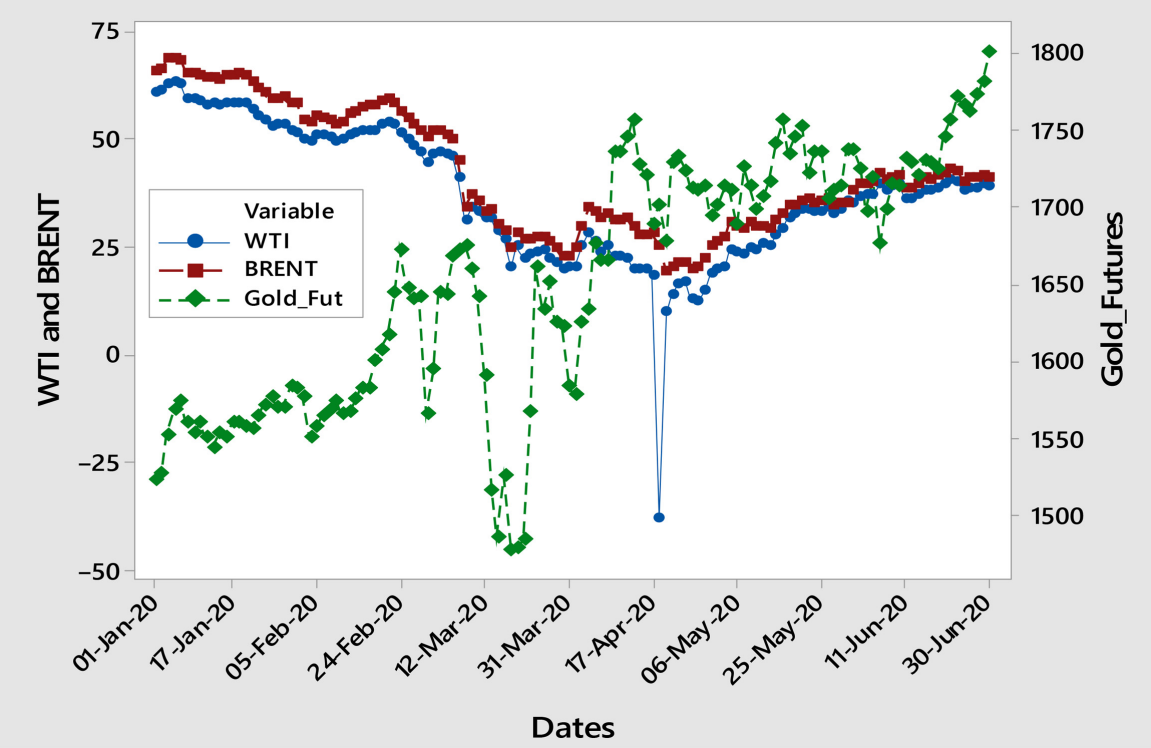

Figure 5.

Time-series plot of crude oil and gold prices during the pandemic period

Table 3 explains the behavior of the investor's fear and panic amid the pandemic outbreak. VIX is the registered trademark of the Chicago Board Options Exchange (CBOE), popularly regarded as a barometer of the investor's fear and anxiety due to tail events. Whaley (2000) considers VIX as the investor's fear index and calculates in percentage terms using observed options prices. Reading of VIX between 15 and $30 \%$ is found to be under control, but 


\section{EJMBE 30,3}

\section{0}

Figure 6.

Time-series plot of crude oil and US dollar index during the pandemic period

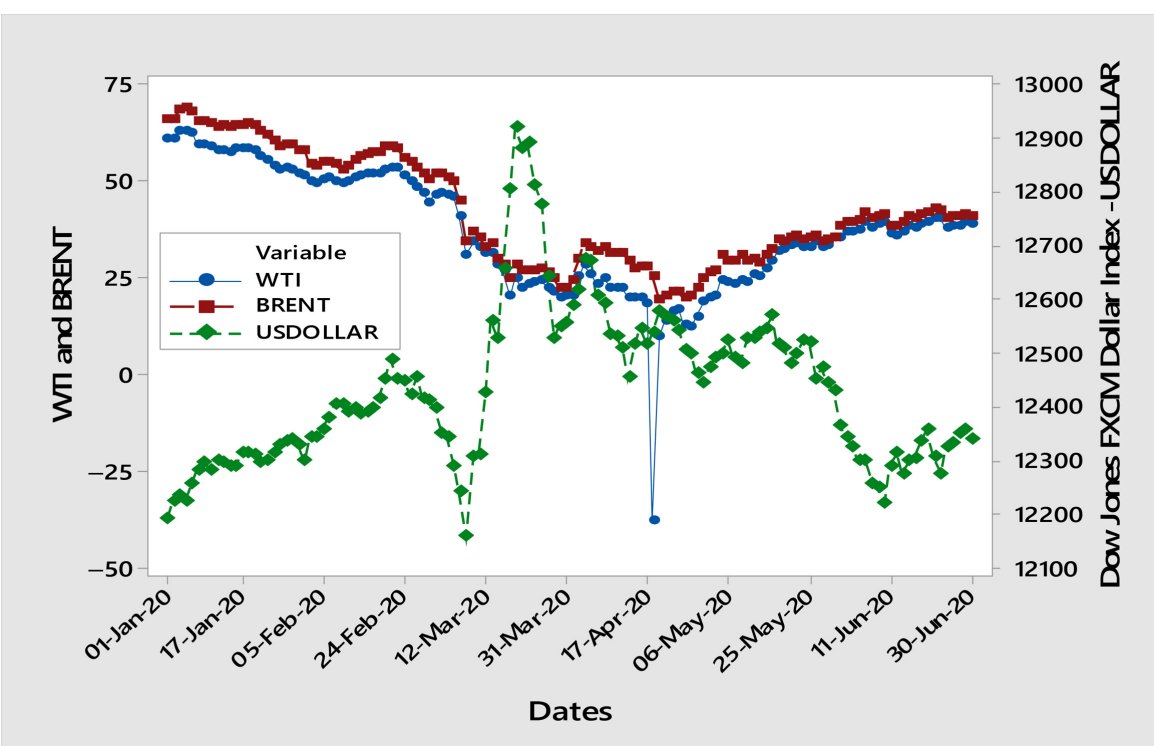

\begin{tabular}{lcccc}
\hline & OVX & OIV & VIX & VXD \\
\hline Mean & 85.4624 & 211.6292 & 32.4493 & 32.8595 \\
Maximum & 325.1500 & 1418.4700 & 82.6900 & 67.0700 \\
Minimum & 27.6600 & 27.4300 & 12.1000 & 11.4600 \\
Std. dev & 55.6785 & 241.2355 & 16.3535 & 15.0672 \\
Observations & 130 & 130 & 130 & 130 \\
\hline
\end{tabular}

measuring more than $30 \%$ indicates excessive uncertainty in the market. The average level of crude oil market volatility OVX (OIV) appears to be $85.46 \%(211.62 \%)$, which is relatively high from the normal range. The maximum and minimum level of OVX (OIV) was found, respectively, $325.15 \%$ (27.66) and $1418.47 \%(27.43 \%)$. One can see that in relation to EMV (VIX and VXD), crude oil market volatility seems to be very high, which indicate that there is a lack of risk management products like futures and options.

Table 4 summarizes the correlation matrix between crude oil prices and a pandemic outbreak. The association of oil with other asset classes, e.g. Tisdell (2020), discusses various economic, social and political issues amid Covid-19 and explains how economic activity affects the production and labor market and, eventually, impact the energy market. Panel A of Table 4 shows the correlation coefficient between crude oil price and pandemic indicators. We can see that global crude oil is adversely linked with the news related to the pandemic outbreak, and the WCSENI shows a positive impact on the oil. We document this statistical phenomenon in our regression model. Panel B describes the association of crude oil with other asset classes; one of the essential observations is that gold and US dollar are statistically significant and negatively associated. It implies that a fall in crude oil led to a rise in the gold price, and the US dollar becomes stronger. DJCI and global crude oil are closely associated. Hence, in our empirical model, we include some of the control variables: stock index, commodity and gold, and US dollar index. Panel C displays the market participant's 


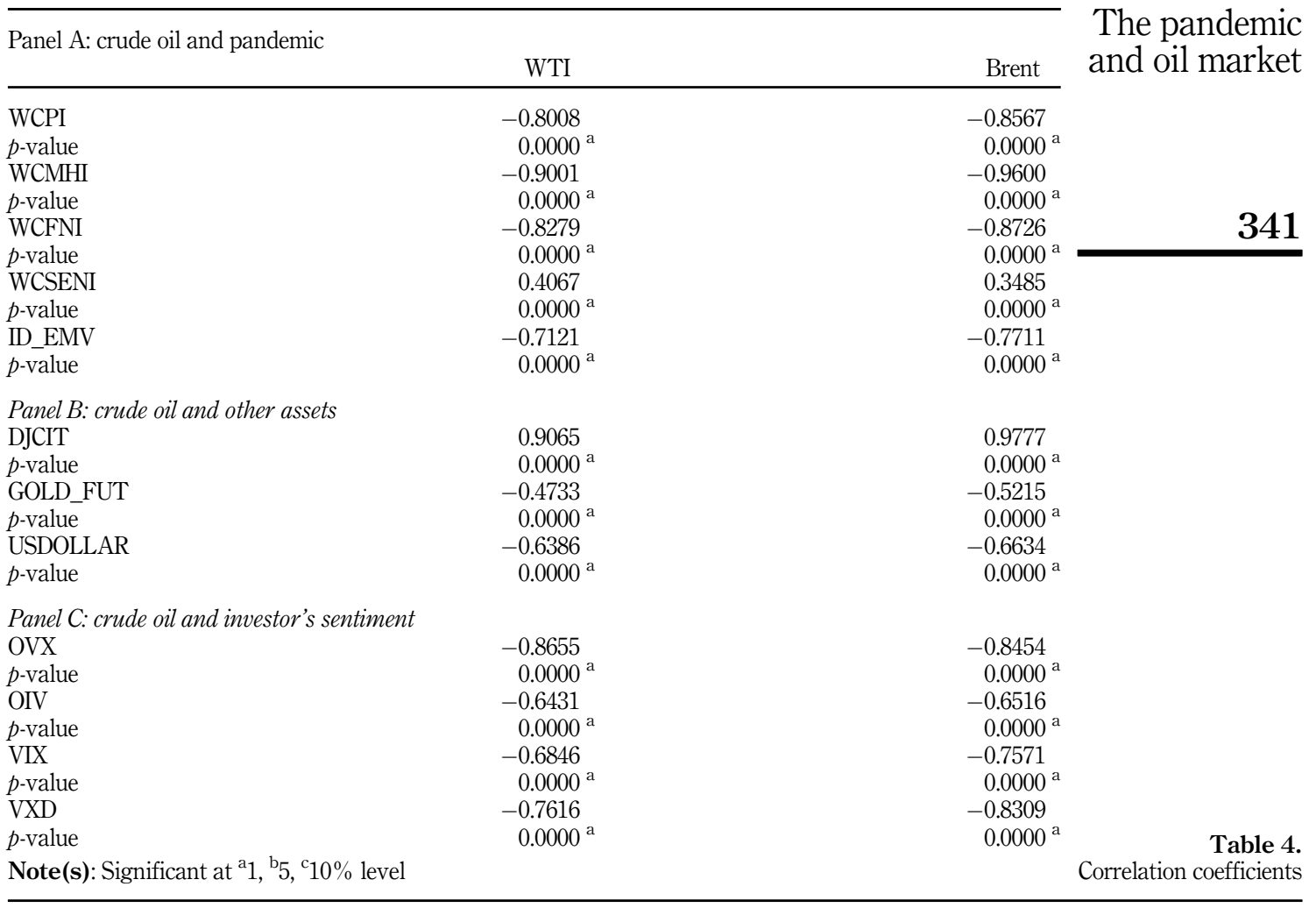

overreaction measured in terms of the volatility index (OVX, OIV, VIX, VXD) when some unexpected tail events happen in the market. One can see that crude oil and expected market volatility (both commodity and stock market) are significantly adversely associated.

\section{Empirical model and hypothesis development}

\subsection{Pandemic and dynamic of global crude oil}

Our empirical model on the pandemic infection is expressed in terms of ordinary least squares (OLS) and interaction dummy variables. Some of the statistical evidence presented in the previous section represents that global crude oil prices appear to be more volatile during the period of the pandemic outbreak (e.g. Al-Awadhi et al., 2020; Apergis and Apergis, 2020; Haroon and Rizvi, 2020; Zhang et al., 2020). In our regression model, we consider logtransformed returns of the prices of WTI and Brent. Besides, we consider pandemic indices and log-transformed returns of other asset classes. The infectious pandemic specification is:

$$
R_{t}^{i}=\beta_{0}+\beta_{j 1} D_{j t} X_{t}+\beta_{k 2} Z_{t}+e_{t}
$$

where $R_{t}^{i}=$ is the returns associated with WTI and Brent crude oil prices. $\beta_{0}=$ is the intercept coefficient that measures the other economic and health crises for the sample period. $D_{j t}=$ is the dummy variable that assumes 1 for Q1(Q2), otherwise 0 (here, Q1 regarded as Phase I of the pandemic outbreak and Q2 Phase II). $X_{t}=$ is the vector of various pandemic indices, and here we take the log transformation of (1 + Pandemic index) (Haroon and Rizvi, 2020; Salisu 
EJMBE 30,3

\section{2}

and Akanni, 2020). $\beta_{j 1}=$ is the slope coefficient measure the effects of the Covid-19 outbreak on the crude oil market during the first and second quarter of 2020. If pandemic infection affecting adversely than a variant of $\beta_{j 1}$ should appear negative and statistically significant. The coefficient associated with the WCSENI should appear positive if sentiment improves. $Z_{t}=$ is the vector of various control and other asset class associated with the crude oil market. $\beta_{k 2}=$ is the slope that measures the changes in the other commodities, gold price, US dollar and equity market.

$$
\log \mathrm{IMPVOL}_{t}^{i}=\delta_{0}+\delta_{j 1} D_{j t} X_{t}+\delta_{k 2} R_{t}^{\text {Underlying }}+e_{t}^{\prime}
$$

where $\log \mathrm{IMPVOL}_{t}^{i}=$ is the log-transformed values of volatility indexes (OVX and OIV). $\delta_{0}=$ is the intercept coefficient that should appear positive and statistically significant if other relevant events occur, such as economic, political and health emergency. $D_{j t} X_{t}=$ is the pandemic interaction term, as explained in the previous paragraph. $\delta_{j 1}=$ is the infectious pandemic coefficient, should be measured positive and statistically significant, by conventions pandemic news disrupt the investor's sentiment and increases the panic. $R_{t}^{\text {Underlying }}=$ is the control variable chosen as underlying of the OVX and OIV, the respective underlying on which crude oil options are written, USO and WTI. $\delta_{k 2}=$ is the slope coefficient explaining the relation between volatility and returns; it should be calculated negative and significant.

Our general empirical hypothesis is: (1) equation (1) attempts to test $\mathrm{H}_{1}$ "pandemic and global crude oil prices are adversely associated." (2) Equation (2) sets to test $\mathrm{H}_{2}$ "crude oil market volatility (investor's sentiment) and pandemic news and infection growth are positively associated.”

\subsection{Spillover and connectedness studies}

Diebold and Yilmaz (2009) framework explains the mechanism of vector autoregressions (VARs) developed for the volatility spillover measure based on forecast error variance decompositions. Diebold and Yilmaz (2012) outstretched their earlier work and examine daily volatility spillovers across the equity market, bond, foreign exchange and markets of commodities concerning GFC 2008-2009. VAR allows us to calculate the impulse response function and variance decomposition. Diebold and Yilmaz encompass their work to decay the total spillover in directional spillover using generalized VAR (GVAR). To transact with market connectedness amid Covid-19, we employ the Diebold and Yilmaz GVAR framework in which error variance decompositions are invariant among variable ordering and allow us to discover directional volatility spillover (i.e. TO and FROM). To prob into connectedness and volatility spillover, we analyze log-transformed returns calculated for the WTI, Brent, gold, US dollar index, DJIA and volatilities are articulated as absolute values of returns. For example, prominent studies (Taylor, 1986; McKenzie, 1999; Ederington and Guan, 2000) frequently use absolute returns for the various asset classes and show that it gives improved volatility forecasts than models based on squared returns.

\section{Results and discussion}

Table 5 shows the regression output concerning pandemic infection in the crude oil markets. We present analysis in two phases, Phase I (2020Q1) is the initial stage of the pandemic outbreak started from the Wuhan city of China, and then it spread across the globe. Phase II (2020Q2) is the nationwide health emergency status in which administration became more active with three Ts, trace, test and treatment; moreover, government bailout package for the industry, lockdown, social distancing and international travel ban. Phase I appears to be more uncertain about the uncontained impact of Covid-19 on economic activity. Hence, investors 


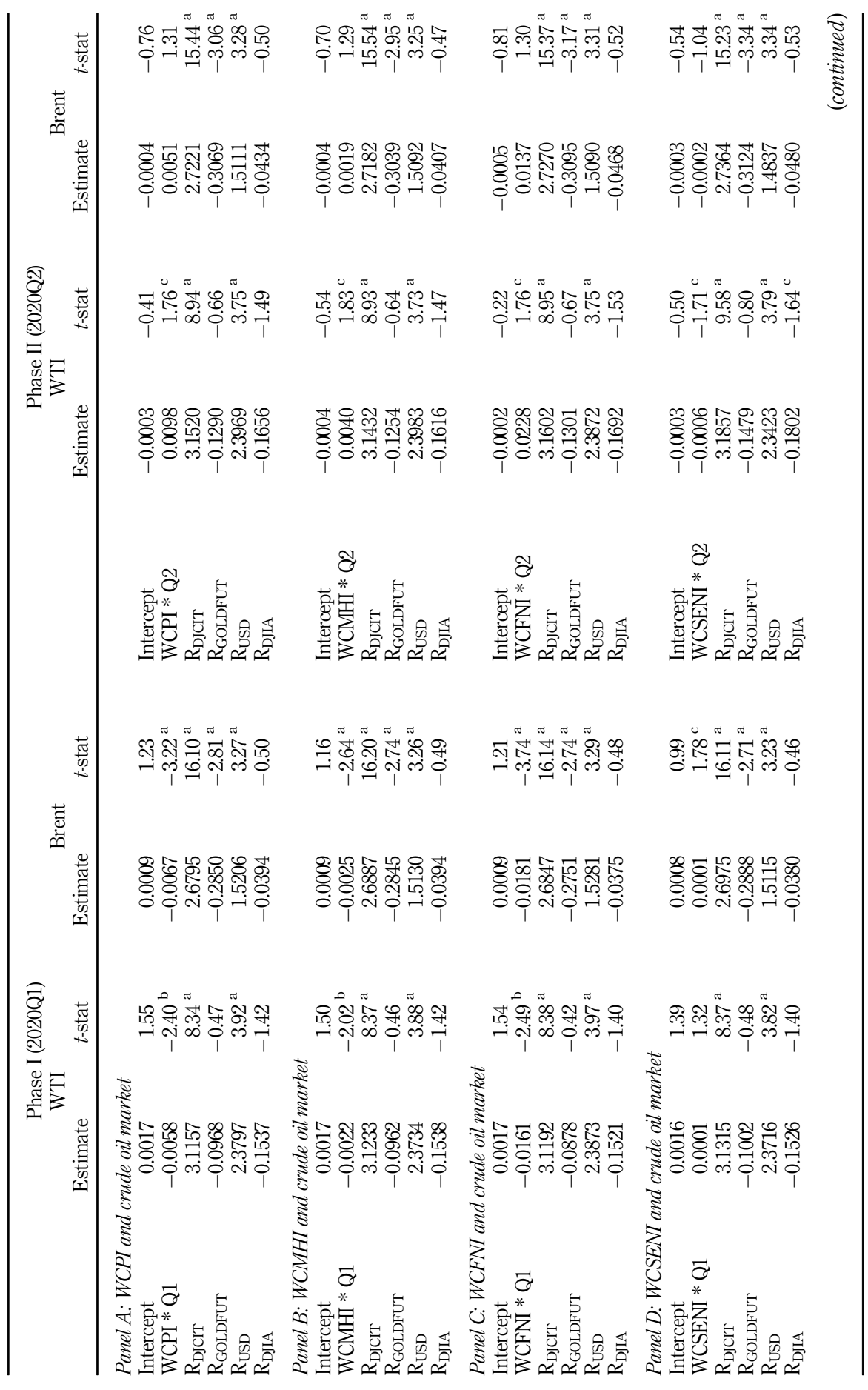

The pandemic and oil market

343

Table 5.

Covid-19 pandemic outbreak and crude oil market 


\section{EJMBE 30,3}

344

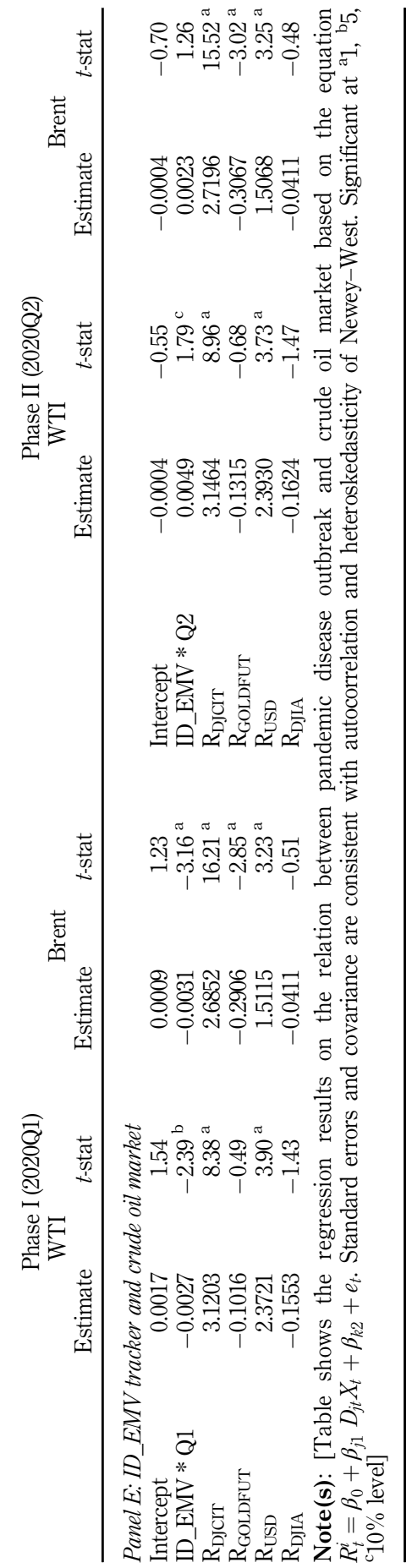

Table 5. 
are more concerned about their portfolio rebalancing and risk management. Our study considers various pandemic indicators; Panel A of Table 5 shows the impact of Covid-19 in terms of the WCPI. It is evident that the slope coefficient of WCPI * Q1 (an interaction dummy term) appears to be $-0.0056(-0.0067)$, with significant $t$-statistic, which implies that during the first phase of an infection outbreak, WTI and Brent phased an adverse market movement and traded historically low. But, it seemed that WTI and Brent were marginally improving in the second phase of the pandemic growth. Also. Panel B exhibits the effects of media hype created during the first and second phases. WCMHI seems to be impacting negatively crude oil markets and gradually showing a positive effect in the second phase of the virus outbreak. Markets are efficient, and asset prices impound the latest market-relevant information, irrespective of the nature of good news or fake news. Panel $\mathrm{C}$ explains the crude oil market behavior during pandemic fake news spread. WCFNI (e.g. Haroon and Rizvi, 2020) measures the amount of flow of fake news about Covid-19. One can see that during the first phase of the Covid-19 infections, the oil market pays close attention to the fake news, and oil prices responded adversely.

Table 5, Panel D demonstrates the statistical evidence concerning Covid-19 world sentiment influencing the commodity markets. WCSENI speaks about the general confidence among the people about future saving and investment, which is quite visible in terms of global commodity prices. During the first phase of the pandemic outbreak, WCSENI does not significantly explain the crude oil market, but amidst the second phase, it shows an adverse impact on the oil market. It implies that market participants are still worried and have a panic about future consumption and investment. Panel $\mathrm{E}$ brings some novel evidence based on the infectious disease market volatility tracker (ID-EMV). In particular, the tracker analyzes the news published in the major financial and economic press, and it is obvious market participants refer to that news and revise their future investment strategies accordingly. We can see that estimates of ID-EMV * Q2 appear to be $-0.0027(-0.0031)$, with significant $t$-statistics at 5 and $1 \%$ level. It indicates that infectious disease impacts the crude oil market and yields negative returns during the first phase of pandemic development. Further, one can see that during the second phase, the ID-EMV index falls (Figure 1) and shows a positive impact on the crude oil market. For example, Saefong and Watts (2020) report a recent oil demand has improved because of enabling lockdown restrictions, production cuts by $\mathrm{OPEC}+$ may be premature given the state of the worldwide economy and increasing coronavirus cases in the USA.

Table 5 shows that the intercept coefficient was positive in the first phase and negative in the second phase across all the panels. It implies that during the initial growth of the Covid-19, other macroeconomic and political events were in favor of the market. Simultaneously, during the second phase amidst pandemic outbreak, lockdown, lack of energy demand, excess supply of crude oil and ban on international travel hurt the global crude oil market. Still, economic activities are not in a normalcy state, and crude is struggling for the best global price. Looking at the control variables, the DJCIT index and the US dollar index showed a positive impact. By contrast, the DJIA and gold price showed an adverse effect across both phases of Covid-19 infection.

Table 6 exhibits the behavior of the oil market volatility amid Covid-19 infection; OVX and OIV are the oil volatility indices; the preceding one is based on the options written on the USO oil fund, and next one options on WTI futures. OVX and OIV measure the investor's panic subject to tail events in the crude oil markets; both the indices are available in real time and expressed in percentage term. Looking at the first three pandemic indices (WCPI, WCMHPI, WCFNI - Phase I), the slope coefficients are, respectively, $0.23(0.25), 0.09(0.10)$ and $0.63(0.66)$ with significant $t$ statistics. It means the pandemic has increased the expected crude oil market volatility, and fake news does contain some disruptive elements to distract the energy traders. On the other hand (Phase II), the respective estimates of OVX(OIV) are $0.31(0.62), 0.11(0.25)$ and 0.75 (1.47)
The pandemic and oil market 
EJMBE
30,3

\section{6}

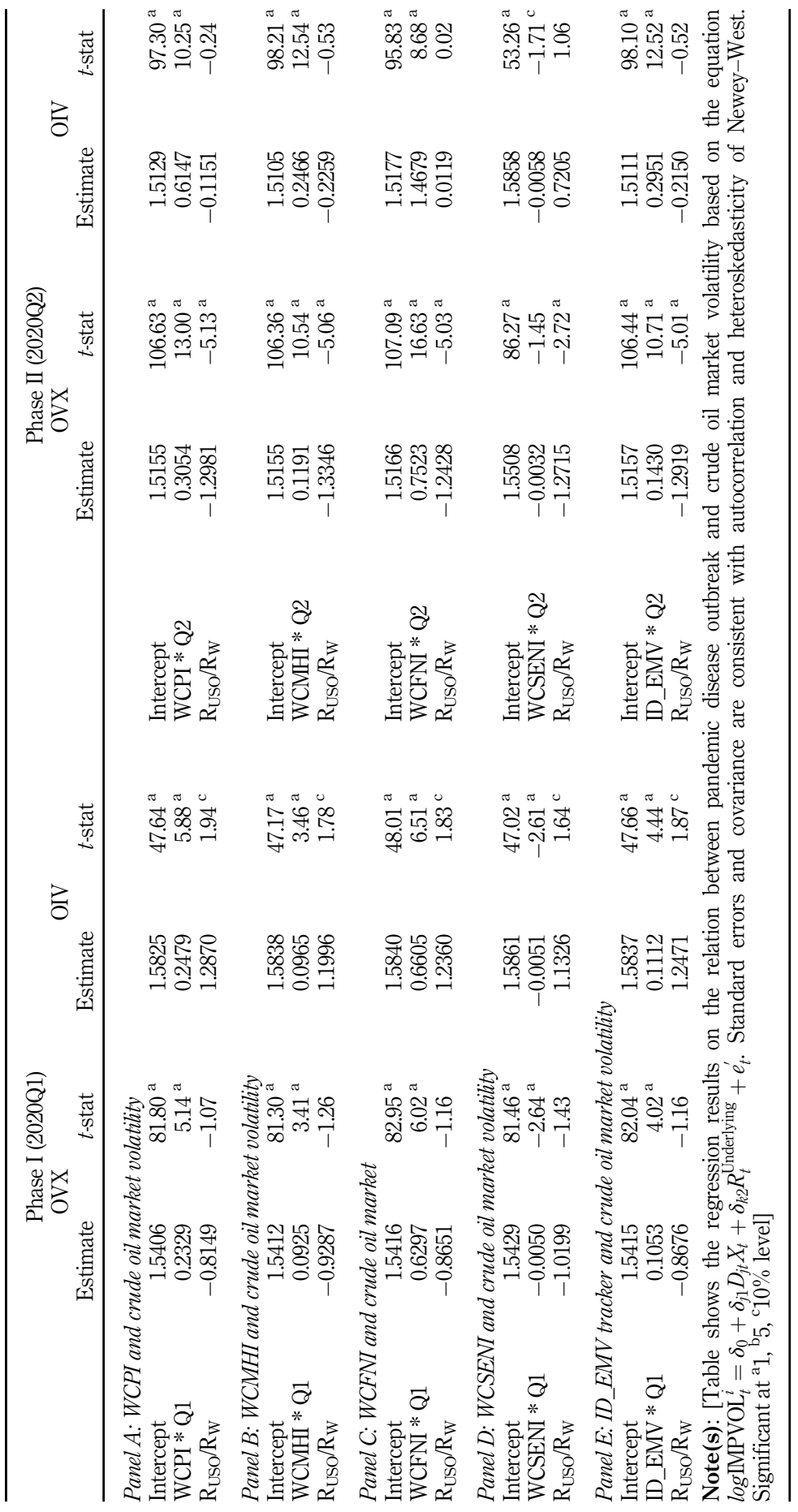

Table 6.

Covid-19 pandemic outbreak and crude oil market volatility 
with significant $t$-score; it implies that both the phases of pandemic outbreak disrupt the investor sentiment. Still, impacts are more visible in the second phase of the pandemic infection. The fourth world pandemic sentiment index seems to decay the implied volatility in both the phases of the Covid-19 outbreak. Last, the effects of pandemic infection gauged in terms of IDEMV show an adverse impact on the oil volatility index. The significant positive slope indicates that infectious diseases increase the investor panic and anxiety; eventually, it led to a rush for the over-reliance on the hedge funds (here, options) with an extra premium. The slope of the Brent (OIV) appears more significant than the WTI (OIV), which indicates that there is a shortage of put options to protect the future oil trading uncertainty.

Table 7 shows the volatility spillover across the crude oil market, gold, US dollar and equity markets. There have been several pieces of evidence in the literature (e.g. Diebold and Y1lmaz, 2009; Diebold and Y1lmaz, 2012; Antonakakis, 2012; Antonakakis and Gabauer, 2017; Antonakakis et al., 2018 and Hung, 2019) that establish the directional volatility relation and market connectedness among various financial assets. Hence, we model the returns-based volatility for the commodities and equity market to see the spillover and market connectedness between those assets. Based on the Diebold and Yilmaz (2012) framework, we fit the GVAR model to decompose the pandemic shock TO and FROM based on the impulse response functions and variance decomposition (Table 7). The crude oil volatility spillover dynamics are presented using a rolling sample in terms of total spillovers, directional spillovers and net spillover (Figures A1, A2 and A3). Table 7 is to be designated as a volatility spillover table. Table 7 represents $i j$ th entry estimated contribution $T O$ the forecast error variance that is market $i$ coming FROM shocks to market $j$. The table provides the decomposition of the total volatility spillover index in an input-output mechanism. The sum of the off-diagonal elements (columns) shows contributions $T O$ others, while the sum of the row's contributions FROM others and the "from minus to" show net spillovers (the last row of the table). The TCI is shown on the right-side corner.

First, we look at the contribution FROM others (sum of the off-diagonal rows); it seems that the highest directional spillover was received by WTI with $47.45 \%$ during the pandemic period, while second-largest spillover in Brent. Further, we can see the contribution $T O$ others (sum of the off-diagonal columns) the gross directions spillover contributed by Brent $53.92 \%$ TO others and second considerable directional spillover from equity market $43.78 \%$ TO other asset classes. Moreover, looking at the Net directional spillovers (Figures A1, A2 and A3), it was found to be largest for the equity market DJIA $14.9 \%=(43.779-28.879)$ and from others to the gold market $-16.42 \%=(13.625-30.07)$. The non-directional volatility contributions shown in the right-lower corner, which appears to be $34.53 \%$, indicate that, on average, the $35 \%$ volatility forecast error variance contributed from spillover in the crude oil market, gold, US dollar and equity market.

\begin{tabular}{lcrcccc}
\hline & WTI & Brent & DJIA & Gold & USDOLLAR & $\begin{array}{c}\text { Contribution from } \\
\text { others }\end{array}$ \\
\hline WTI & 52.548 & 32.767 & 9.605 & 2.576 & 2.503 & 47.452 \\
BRENT & 27.37 & 58.047 & 9.125 & 1.894 & 3.563 & 41.953 \\
DJIA & 4.728 & 10.711 & 71.121 & 4.962 & 8.478 & 28.879 \\
Gold & 4.12 & 6.131 & 11.357 & 69.93 & 8.461 & 30.07 \\
US-DOLLAR & 2.094 & 4.312 & 13.692 & 4.22 & 75.682 & 24.318 \\
Contribution TO others & 38.312 & 53.922 & 43.779 & 13.652 & 23.006 & 172.671 \\
Contribution including & 90.86 & 111.969 & 114.9 & 83.582 & 98.688 & TCI $=34.534$ \\
own & & & & & & \\
Net spillovers & -9.14 & 11.969 & 14.9 & -16.418 & -1.312 &
\end{tabular}

The pandemic and oil market

$-$


EJMBE 30,3

\section{8}

Table 8.

Oil markets' expected volatility (OVX) amid Covid-19

\section{Robustness check}

Table 8 shows further validation of the empirical results reported in the above sections. In this table, we set monthly dummies from January to June 2020, e.g. for the pandemic month of January, D1 = 1, otherwise 0 , and similarly for other months. In our regression model, we add month-wise interaction terms with various indices of a pandemic outbreak. During regression estimation, we allow dummies February-June; hence, the intercept coefficient measures the effects of January. We can see that the WCPI, WCMHI and WCFNI show an adverse impact on the future energy market volatility (OVX). The changes in the OVX during January and March were found to be positive and showed more fear among the energy traders. Further, the WCSENI exhibits an asymmetric impact on the expected oil market volatility, lower the sentiment higher fear among the energy traders. Moreover, the infectious diseases market volatility index also depicts an adverse investor sentiment $(\mathrm{OVX})$ in the energy market.

\section{Conclusion}

The global benchmark of crude oil WTI and Brent has perceived an unprecedented overreaction during the first quarter of the pandemic year 2020. The dynamics of global crude oil have been extremely transformed over the past decade. Hence, an analysis has been presented in two phases. Phase I (2020Q1) is the initial stage of the pandemic outbreak started from the Wuhan city of China, and then it spread across the globe. Phase II (2020Q2) is the state nationwide health emergency in which administration becomes more active with three Ts: trace, test and treatment. Moreover, the administration's bailout package for the industry, lockdown, social distancing and international travel ban has decreased global energy demand. Our empirical model and result reported amid Covid-19 are novel in terms of

\begin{tabular}{|c|c|c|c|c|c|c|c|}
\hline 2020 & January & February & March & April & May & June & $\begin{array}{l}\text { Underlying } \\
\text { return }\end{array}$ \\
\hline WCPI & $\begin{array}{l}\text { D1 * } \\
\text { WCPI }\end{array}$ & $\mathrm{D} 2 * \mathrm{WCPI}$ & $\begin{array}{c}\text { D3 } * \\
\text { WCPI }\end{array}$ & $\begin{array}{l}\text { D4 * } \\
\text { WCPI }\end{array}$ & $\begin{array}{l}\text { D5 * } \\
\text { WCPI }\end{array}$ & $\begin{array}{l}\text { D6* } \\
\text { WCP }\end{array}$ & Return \\
\hline Estimate & 1.0598 & -0.1919 & 2.3156 & -0.3989 & -0.8937 & -0.2991 & -165.6608 \\
\hline$t$-stat & $2.12 \mathrm{~b}$ & -0.33 & $3.02 \mathrm{a}$ & -0.09 & -1.17 & -0.92 & $-2.78 \mathrm{a}$ \\
\hline WCMHI & $\begin{array}{c}\text { D1 * } \\
\text { WCMHI }\end{array}$ & $\begin{array}{c}\mathrm{D} 2 * \\
\text { WCMHI }\end{array}$ & $\begin{array}{c}\text { D3* } \\
\text { WCMHI }\end{array}$ & $\begin{array}{c}\text { D4 * } \\
\text { WCMHI }\end{array}$ & $\begin{array}{c}\text { D5 * } \\
\text { WCMHI }\end{array}$ & $\begin{array}{c}\text { D6 * } \\
\text { WCMHI }\end{array}$ & Return \\
\hline Estimate & 0.3499 & -0.0777 & 1.1434 & -0.4539 & -0.3430 & -0.1054 & -164.9771 \\
\hline$t$-stat & $2.19 \mathrm{a}$ & -0.46 & $3.14 \mathrm{a}$ & -0.23 & -1.07 & -0.89 & $-2.79 a$ \\
\hline WCFNI & $\begin{array}{c}\text { D1 * } \\
\text { WCFNI }\end{array}$ & $\begin{array}{c}\mathrm{D} 2 * \\
\text { WCFNI }\end{array}$ & $\begin{array}{c}\text { D3* } \\
\text { WCFNI }\end{array}$ & $\begin{array}{c}\text { D4 * } \\
\text { WCFNI }\end{array}$ & $\begin{array}{c}\text { D5 * } \\
\text { WCFNI }\end{array}$ & $\begin{array}{c}\text { D6* } \\
\text { WCFNI }\end{array}$ & Return \\
\hline Estimate & 3.3156 & -0.6053 & 5.5733 & -0.8415 & -2.5748 & -0.6768 & -167.0732 \\
\hline$t$-stat & $1.69 \mathrm{c}$ & -0.31 & $2.85 \mathrm{a}$ & -0.09 & -1.29 & -0.74 & $-2.82 \mathrm{a}$ \\
\hline WCSENI & D1 * & $\begin{array}{c}\mathrm{D} 2 \\
\end{array}$ & D3 * & D4 * & D5 * & D6 * & Return \\
\hline & WCSENI & WCSENI & WCSENI & WCSENI & WCSENI & WCSENI & \\
\hline Estimate & -0.0137 & 0.0048 & -0.0709 & -0.0186 & 0.0548 & 0.0219 & -167.9182 \\
\hline$t$-stat & $-2.50 \mathrm{a}$ & 0.44 & $-3.40 \mathrm{a}$ & -0.12 & 1.15 & 0.62 & $-2.84 \mathrm{a}$ \\
\hline ID_EMV & D1 * & $\mathrm{D} 2 *$ & D3 $*$ & $\mathrm{D} 4 *$ & D5 * & D6 * & Return \\
\hline & ID_EMV & ID_EMV & ID_EMV & ID_EMV & ID_EMV & ID_EMV & \\
\hline Estimate & 0.9088 & $-\overline{0} .1110$ & $\overline{1} .1426$ & -0.4173 & -0.3988 & -0.1480 & -165.5831 \\
\hline$t$-stat & $2.09 \mathrm{a}$ & -0.40 & $3.21 \mathrm{a}$ & -0.18 & -1.11 & -1.14 & $-2.79 a$ \\
\hline
\end{tabular}

Note(s): [Table shows the regression results on the relation between pandemic disease outbreak and crude oil market volatility based on monthly dummies D1-D6. An interaction term has been added with various pandemic indices with monthly dummies. Standard errors and covariance are consistent with autocorrelation and heteroskedasticity of Newey-West. Significant at ${ }^{\mathrm{a}} 1,{ }^{\mathrm{b}} 5,{ }^{\mathrm{c}} 10 \%$ level] 
employing a news-based index of the pandemic, which are based on the content analysis and text search using NLP with the aid of computer algorithms.

Empirical evidence shows that EMV (VIX and VXD) crude oil market volatility (OVX and OIV) seem to be very high, indicating a lack of risk management products like futures and options. It is apparent from the study that global crude oil is adversely linked with the news related to the pandemic outbreak, and the WCSENI shows a positive impact on the oil market. Phase I appear to be more uncertain about the uncontained effect of Covid-19 on the economic activity, and market agents are more concerned about their portfolio rebalancing and risk management. The WCFNI during the first phase of the Covid-19 infections, the oil market paid close attention to the fake news, and oil prices responded adversely. Interestingly, we have observed that infectious disease impacts the crude oil market and yield negative returns during the first phase of pandemic development. We have noticed that during the initial growth of the Covid-19 infection, other macroeconomic and political events were remaining in favor of the market. At the same time, during the second phase amidst the pandemic outbreak, it hurts the global crude oil market. We find that infectious diseases increase investor panic and anxiety. Eventually, it led to a rush for the over-reliance on the hedge funds (e.g. options) with an extra premium.

For the first time in the past decade, Brent traded at its low US $\$ 19.33 / \mathrm{b}$. Looking at the global environment where we can see Covid-19 still spreading but global demand continuing to pick up due to relaxation in the travel and lockdown conditions, one can expect oil by the end of this year and into next year touching towards the US\$50/b range. The recent recovery of the global crude is due to production cuts from Russia and OPEC negotiations. A resurrection of Covid-19 cases in the USA and a gloomy economic forecast, with oil prices on track to hit their most significant historical decline and again in near future excess supply and weak demand, will be the main concern for the energy traders. The sustainable global prices of WTI and Brent depending upon the edge due to increasing US and European tension with China. Most of the countries' economic activities are on track amidst increased cases of Covid-19 and planning to fight for the second wave by the end of 2020. Hence, OPEC plus has recognized that further-production cut could be a dangerous call if the second wave of Covid-19 outbreaks.

\section{Notes}

1. https://coronavirus.ravenpack.com/worldwide/cases Accessed on July 19, 2020.

2. https://coronavirus.ravenpack.com/worldwide/panic and other covid-19 related indexes.

3. http://www.policyuncertainty.com/infectious_EMV.html.

4. The coronavirus panic index measures the level of news chatter that makes reference to panic or hysteria and coronavirus. Values range between 0 and 100, where a value of 7.00 indicates that $7 \%$ of all news globally is talking about panic and Covid-19. The higher the index value, the more references to panic found in the media.

5. The coronavirus media hype index measures the percentage of news talking about the novel coronavirus. Values range between 0 and 100, where a value of 75.00 indicates that $75 \%$ of all news globally is talking about Covid-19.

6. The coronavirus fake news index measures the level of media chatter about the novel virus that makes reference to misinformation or fake news alongside Covid-19. Values range between 0 and 100 , where a value of 2.00 indicates that $2 \%$ of all news globally is talking about fake news and Covid-19. The higher the index value, the more references to fake news found in the media.

7. The coronavirus sentiment index measures the level of sentiment across all entities mentioned in the news alongside the coronavirus. The index ranges between -100 and 100 , where a value of 100 is the most positive sentiment, -100 is the most negative and 0 is neutral.

The pandemic and oil market 
EJMBE 30,3

\section{References}

Al-Awadhi, M.A., Al-Saifi, K., Al-Awadhi, A. and Alhamadi, S. (2020), "Death and contagious infectious diseases: impact of the COVID-19 virus on stock market returns", Journal of Behavioral and Experimental Finance, Vol. 27, 100326, doi: 10.1016/j.jbef.2020.100326.

Ali, M., Alam, N. and Rizv, S.A. (2020), "coronavirus (COVID-19)-An epidemic or Pandemic for financial markets", Journal of Behavioral and Experimental Finance, Vol. 27, 100341, doi: 10. 1016/j.jbef.2020.100341.

Antonakakis, N. (2012), "Exchange return co-movements and volatility spillovers before and after the introduction of euro", Journal of International Financial Markets, Institutions and Money, Vol. 22 No. 5, pp. 1091-1109, doi: 10.1016/j.intfin.2012.05.009.

Antonakakis, N. and Gabaue, D. (2017), "Refined measures of dynamic connectedness based on TVPVAR”, MPRA Paper, 78282, available at: https://mpra.ub.uni-muenchen.de/id/eprint/78282.

Antonakakis, N., Cunado, J., Filis, G., Gabauer, D. and Gracia, F.P. (2018), "Oil volatility, oil and gas firms and portfolio diversification”, Energy Economics, Vol. 70, pp. 499-515, doi: 10.1016/j.eneco. 2018.01.023.

Apergis, E. and Apergis, N. (2020), "Can the COVID-19 pandemic and oil prices drive the US partisan conflict index?”, Energy Research Letters, Vol. 1 No. 1, doi: 10.46557/001c.13144.

Arezki, R. and Nguyen, H. (2020), Coping with a Dual Shock: COVID-19 and Oil Prices, available at: https://www.worldbank.org/: https://www.worldbank.org/en/region/mena/brief/coping-with-adual-shock-coronavirus-covid-19-and-oil-prices.

Bakas, D. and Triantafyllou, A. (2020), "Commodity price volatility and the economic uncertainty of pandemics", Economics Letters, 109283, doi: 10.1016/j.econlet.2020.109283.

Baker, M. and Wurgler, J. (2007), "Investor sentiment in the stock market", The Journal of Economic Perspectives, Vol. 21 No. 2, pp. 129-152, doi: 10.1257/jep.21.2.129.

Baker, S.R., Bloom, N., Davisc, S.J. and Kostd, K. (2019), "Policy news and stock market volatility", Policyuncertainty, available at: http://www.policyuncertainty.com/media/Policy $\% 20$ News $\%$ 20and $\% 20$ Stock $\% 20$ Market $\% 20$ Volatility.pdf.

Baker, S.R., Bloom, N., Davis, S.J., Kost, K., Sammon, M. and Viratyosin, T. (2020a), "The unprecedented stock market reaction to COVID-19", White paper-Becker Friedman Institute for economics at UChicago, pp. 1-12, available at: https://stockmarketjumps.com/files/ COVIDMarketReaction.pdf.

Baker, S., Bloom, N., Davis, S.J. and Terry, S.J. (2020b), "COVID-induced economic uncertainty", National Bureau of Economic Research, No. w26983, doi: 10.3386/w26983.

Bolaño-Ortiz, T.R., Puliafito, S.E., Berná-Peña, L.L., Pascual-Flores, R.M., Urquiza, J. and CamargoCaicedo, Y. (2020), "Tmospheric emission changes and their economic impacts during the COVID-19 pandemic lockdown in Argentina”, Sustainability, Vol. 12 No. 20, p. 8661, doi: 10. 3390/su12208661.

Cen, L.L. and Yang, L. (2013), "Investor sentiment, disagreement, and the breadthreturn relationship", Management Science, Vol. 59 No. 5, pp. 1076-1091, doi: 10.1287/mnsc. 1120.1633.

Chen, M.H., Jang, S.S. and Kim, W.G. (2007), "The impact of the SARS outbreak on Taiwanese hotel stock performance: an event-study approach", International Journal of Hospitality Management, Vol. 26 No. 1, pp. 200-212, doi: 10.1016/j.ijhm.2005.11.004.

Chen, C.D., Chen, C.C., Tang, W.W. and Huang, B.Y. (2009), "The positive and negative impacts of the SARS outbreak: a case of the Taiwan industries", The Journal of Developing Areas, pp. 281-293, available at: https://www.jstor.org/stable/40376284.

Chen, C., Liu, L. and Zhao, N. (2020), "Fear sentiment, uncertainty, and Bitcoin price dynamics: the case of COVID-19", Emerging Markets Finance and Trade, Vol. 56 No. 10, pp. 2298-2309, doi: 10. 1080/1540496X.2020.1787150. 
Devpura, N. and Narayan, P.K. (2020), "Hourly oil price volatility: the role of COVID-19", Energy Research Letters, Vol. 1 No. 2, pp. 1-5, doi 10.46557/001c.13683.

Diebold, F.X. and Yilmaz, K. (2009), "Measuring financial asset return and volatility spillovers, with application to global equity markets", The Economic Journal, Vol. 119 No. 534, pp. 158-171, doi: 10.1111/j.1468-0297.2008.02208.x.

Diebold, F.X. and Yilmaz, K. (2012), "Better to give than to receive: predictive directional measurement of volatility spillovers", International Journal of Forecasting, Vol. 28 No. 1, pp. 57-66, doi: 10. 1016/j.ijforecast.2011.02.006.

Donadelli, M., Kizys, R. and Riedel, M. (2017), "Dangerous infectious diseases: bad news for main street, good news for wall street?", Journal of Financial Markets, Vol. 35, pp. 84-103, doi: 10. 1016/j.finmar.2016.12.003.

Ederington, L. and Guan, W. (2000), "Forecasting volatility”, Working paper, University of Oklahoma, Oklahoma.

Ertuğrul, H.M., Güngör, B.O. and Soytaş, U. (2020), "The effect of the COVID-19 outbreak on the Turkish Diesel”, Energy Research Letters, Vol. 1 No. 3, pp. 1-4, doi: 10.46557/001c.17496.

Gil-Alana, L.A. and Claudio-Quiroga, G. (2020), "The COVID-19 Impact on the Asian stock markets", Asian Economics Letters, Vol. 1 No. 2, pp. 1-4, doi: 10.46557/001c.17656.

Gil-Alana, L.A. and Monge, M. (2020), "Crude oil prices and COVID-19: persistence of the shock", Energy Research Letters, Vol. 1 No. 1, doi: 10.46557/001c.13200.

Goodell, J.W. (2020), “COVID-19 and finance: agendas for future research”, Finance Research Letters, Vol. 35, 101512, doi: 10.1016/j.frl.2020.101512.

Haldar, A. and Sethi, N. (2020), "The effect of country-level factors and government intervention on the incidence of COVID-19", Asian Economics Letters, Vol. 1 No. 2, pp. 1-4, doi: 10.46557/001c.17804.

Haroon, O. and Rizvi, S.A. (2020), "COVID-19: media coverage and financial markets behavior-a sectoral inquiry", Journal of Behavioral and Experimental Finance, 100343, doi: 10.1016/j.jbef. 2020.100343.

He, P., Sun, Y., Zhang, Y. and Li, T. (2020), “COVID -19's impact on stock prices across different sectors - an event study based on the Chinese stock market", Emerging Markets Finance and Trade, Vol. 56 No. 10, pp. 2198-2212, doi: 10.1080/1540496X.2020.1785865.

Hung, N.T. (2019), "An analysis of CEE equity market integration and their volatility spillover effects", European Journal of Management and Business Economics, Vol. 29 No. 1, pp. 23-40, doi: 10.1108/EJMBE-01-2019-0007.

Jhawar, P. and Gopalakrishnan, T. (2020), COVID-19: Why the Crisis Is Different for the Crude Oil Industry, available at: https://www.downtoearth.org.in/https://www.downtoearth.org.in/news/ energy/covid-19-why-the-crisis-is-different-for-the-crude-oil-industry-71271.

Kamstra, M.J., Kramer, L.A. and Levi, M.D. (2003), "Winter blues: a SAD stock market cycle", The American Economic Review, Vol. 93 No. 1, pp. 324-343, doi: 10.1257/000282803321455322.

Kaplanski, G. and Levy, H. (2010), "Exploitable predictable irrationality: the FIFA world cup effect on the US stock market", Journal of Financial and Quantitative Analysis, Vol. 45 No. 2, pp. 535-553, doi: 10.1017/S0022109010000153.

Kaplanski, G. and Levy, H. (2012), "The holiday and yom kippur war sentiment effects: the Tel Aviv stock exchange (TASE)", Quantitative Finance, Vol. 12 No. 8, pp. 1283-1298, doi: 10.1080/ 14697688.2010.504225.

Liu, L., Wang, E.Z. and Lee, C.C. (2020), "Impact of the COVID-19 Pandemic on the crude oil and stock markets in the US: a time-varying analysis", Energy Research Letters, Vol. 1 No. 1, doi: 10.46557/ 001c.13154.

Lucey, B.M. and Dowling, M. (2005), "The role of feelings in investor decision-making", Journal of Economic Surveys, Vol. 19 No. 2, pp. 211-237, doi: 10.1111/j.0950-0804.2005.00245.x. 
EJMBE 30,3
McKenzie, M.D. (1999), "Power transformation and forecasting the magnitude of exchange rate changes", International Journal of Forecasting, Vol. 15 No. 1, pp. 49-55, doi: 10.1016/S01692070(98)00066-1.

Narayan, P.K. (2020), "Oil price news and COVID-19-is there any connection?", Energy Research Letters, Vol. 1 No. 1, doi: 10.46557/001c.13176.

Narayan, P.K. (2020a), "Has COVID-19 changed exchange rate resistance to shocks?", Asian Economics Letters, Vol. 1 No. 1, pp. 1-4, doi: 10.46557/001c.17389.

Narayan, P.K. (2020b), "Did bubble activity intensify during COVID-19?", Asian Economics Letters, Vol. 1 No. 2, pp. 1-5, doi: 10.46557/001c.17654.

Norouzi, N. and Fani, M. (2020), "Black gold falls, black plague arise-An Opec crude oil price forecast using a gray prediction model”, Upstream Oil and Gas Technology, Vol. 5, 100015, doi: 10.1016/j. upstre.2020.100015.

Norouzi, N., Rubens, G.Z., Choubanpishehzafar, S. and Enevoldsen, P. (2020), "When pandemics impact economies and climate change: exploring the impacts of COVID-19 on oil and electricity demand in China", Energy Research and Social Science, Vol. 68, 101654, doi: 10.1016/j.erss.2020. 101654.

Paule-Vianez, J., Prado-Román, C. and Gómez-Martínez, R. (2020), "Economic policy uncertainty and Bitcoin. Is Bitcoin a safe-haven asset?", European Journal of Management and Business Economics, Vol. 29 No. 3, pp. 347-363, doi: 10.1108/EJMBE-07-2019-0116.

Pellejero, S. (2020), Oil Prices Fall as Rising Covid-19 Cases Prompt Demand Concerns; Investors Also Eye Rising Crude, available at: https:/www.wsj.com/articles/oil-prices-fall-as-rising-covid-19cases-prompt-demand-concerns-11593187200.

Phan, D.H. and Narayan, P.K. (2020), "Country responses and the reaction of the stock market to COVID-19 - a preliminary exposition", Emerging Markets Finance and Trade, Vol. 56 No. 10, pp. 2138-2150, doi: 10.1080/1540496X.2020.1784719.

Polemis, M. and Soursou, S. (2020), "Assessing the impact of the COVID-19 pandemic on the Greek energy firms: an event study analysis", Energy Research Letters, Vol. 1 No. 3, pp. 1-5, doi: 10. 46557/001c.17238.

Qin, M., Zhang, Y.C. and Su, C.W. (2020), "The essential role of pandemics: a fresh insight into the oil market”, Energy Research Letters, Vol. 1 No. 1, pp. 1-6, doi: 10.46557/001c.13166.

Saefong, M.P. and Watts, W. (2020), "Oil settles lower, posting modest change for week as rise in coronavirus cases stokes demand worries", available at: https://www.marketwatch.com/: https://www.marketwatch.com/story/oil-prices-edge-lower-as-rise-in-coronavirus-cases-stokesdemand-worries-2020-07-17.

Salisu, A. and Adediran, I. (2020), "Uncertainty due to infectious diseases and energy market volatility”, Energy Research Letters, Vol. 1 No. 2, doi: 10.46557/001c.14185.

Salisu, A.A. and Akanni, L.O. (2020), "Constructing a global fear index for the COVID-19 pandemic", Emerging Markets Finance and Trade, Vol. 56 No. 10, pp. 2310-2331, doi: 10.1080/1540496X.' 2020.1785424.

Salisu, A.A. and Sikiru, A.A. (2020), "Pandemics and the Asia-pacific Islamic stocks", Asian Economics Letters, Vol. 1 No. 1, pp. 1-5, doi: 10.46557/001c.17413.

Sovacool, B.K., Rio, D.F. and Griffiths, S. (2020), "Contextualizing the Covid-19 Pandemic for a carbonconstrained world: insights for sustainability transitions, energy justice, and research methodology", Energy Research and Social Science, Vol. 68, 101701, doi: 10.1016/j.erss.2020. 101701.

Taylor, S.J. (1986), Modelling Financial Time Series, John Wiley \& Sons, New Delhi.

Tisdell, C.A. (2020), "Economic, social and political issues raised by the COVID-19 Pandemic", Economic Analysis and Policy, Vol. 68, pp. 17-28, doi: 10.1016/j.eap.2020.08.002. 
Vidya, C.T. and Prabheesh, K.P. (2020), "Implications of COVID-19 pandemic on the global trade networks", Emerging Markets Finance and Trade, Vol. 56 No. 10, pp. 2408-2421, doi: 10.1080/ 1540496X.2020.1785426.

The pandemic and oil market

Wang, Y.H., Yang, F.J. and Chen, L.J. (2013), "An investor's perspective on infectious diseases and their influence on market behavior", Journal of Business Economics and Management, Vol. 14 No. sup1, pp. S112-S127, doi: 10.3846/16111699.2012.711360.

Whaley, R.E. (2000), "The investor fear gauge”, Journal of Portfolio Management, Vol. 26 No. 3, pp. 12-17.

Yuen, K.S. and Lee, T.M. (2003), "Could mood state affect risk-taking decisions?", Journal of Affective Disorders, Vol. 75 No. 1, pp. 11-18, doi: 10.1016/S0165-0327(02)00022-8.

Zhang, D., Hu, M. and Ji, Q. (2020), "Financial markets under the global Pandemic of COVID-19", Finance Research Letters, 101528, doi: 10.1016/j.frl.2020.101528. 
EJMBE
30,3

354
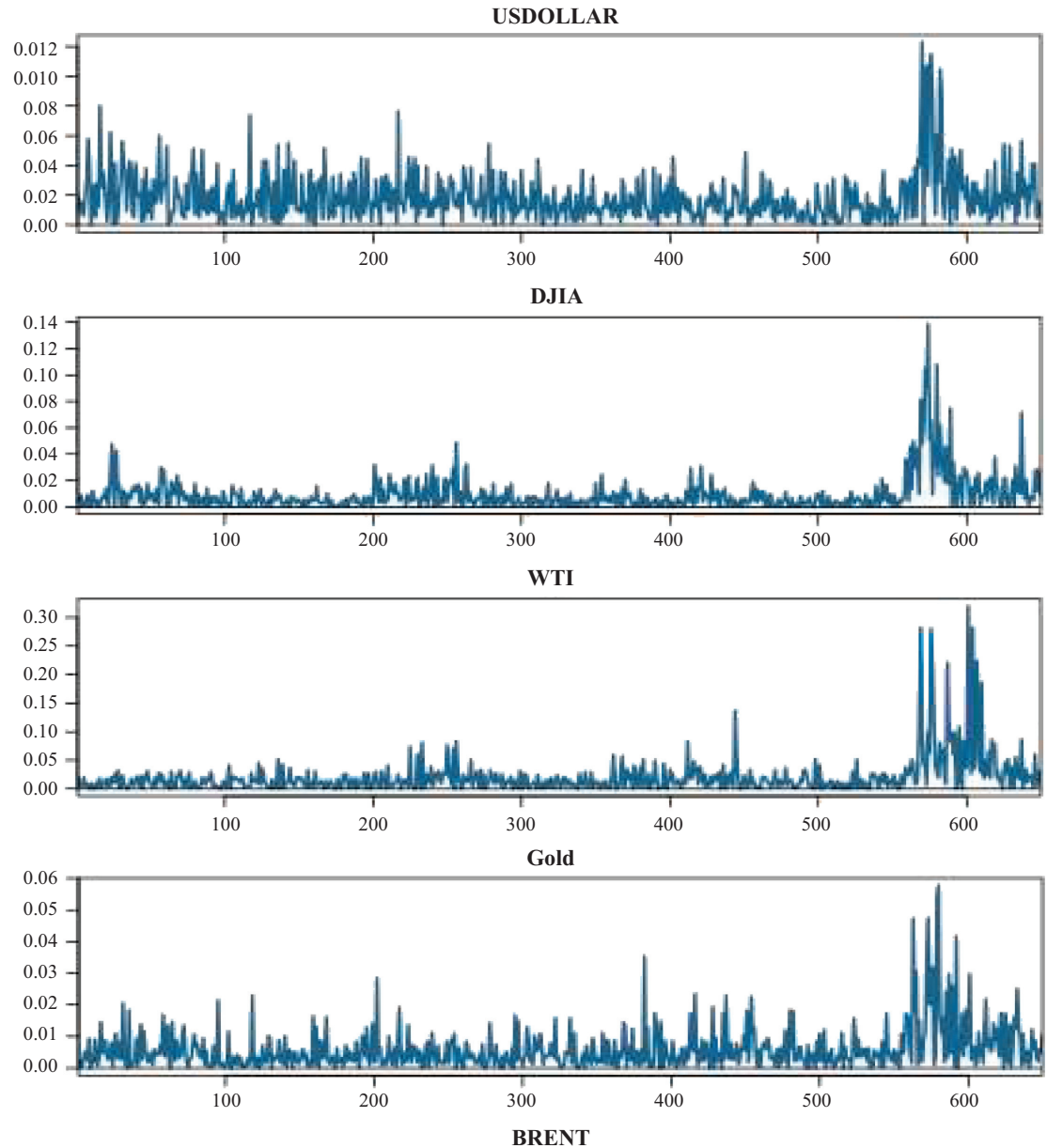

Figure A1.

Absolute returns volatility

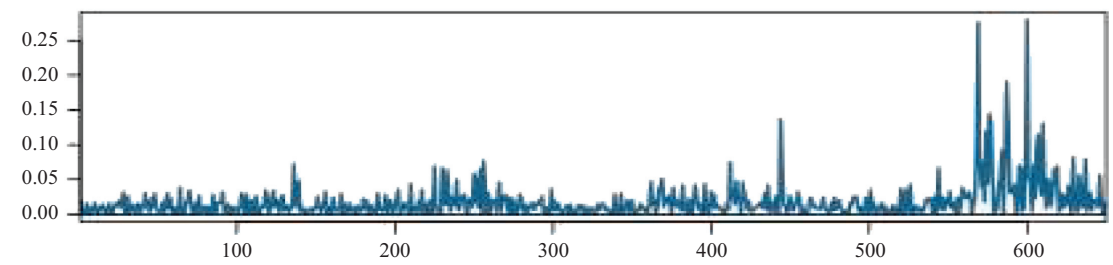


The pandemic and oil market

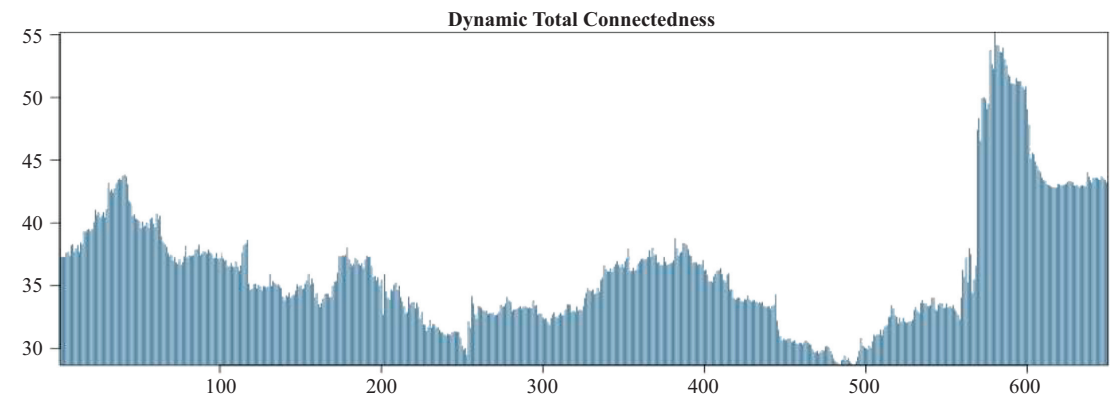

355
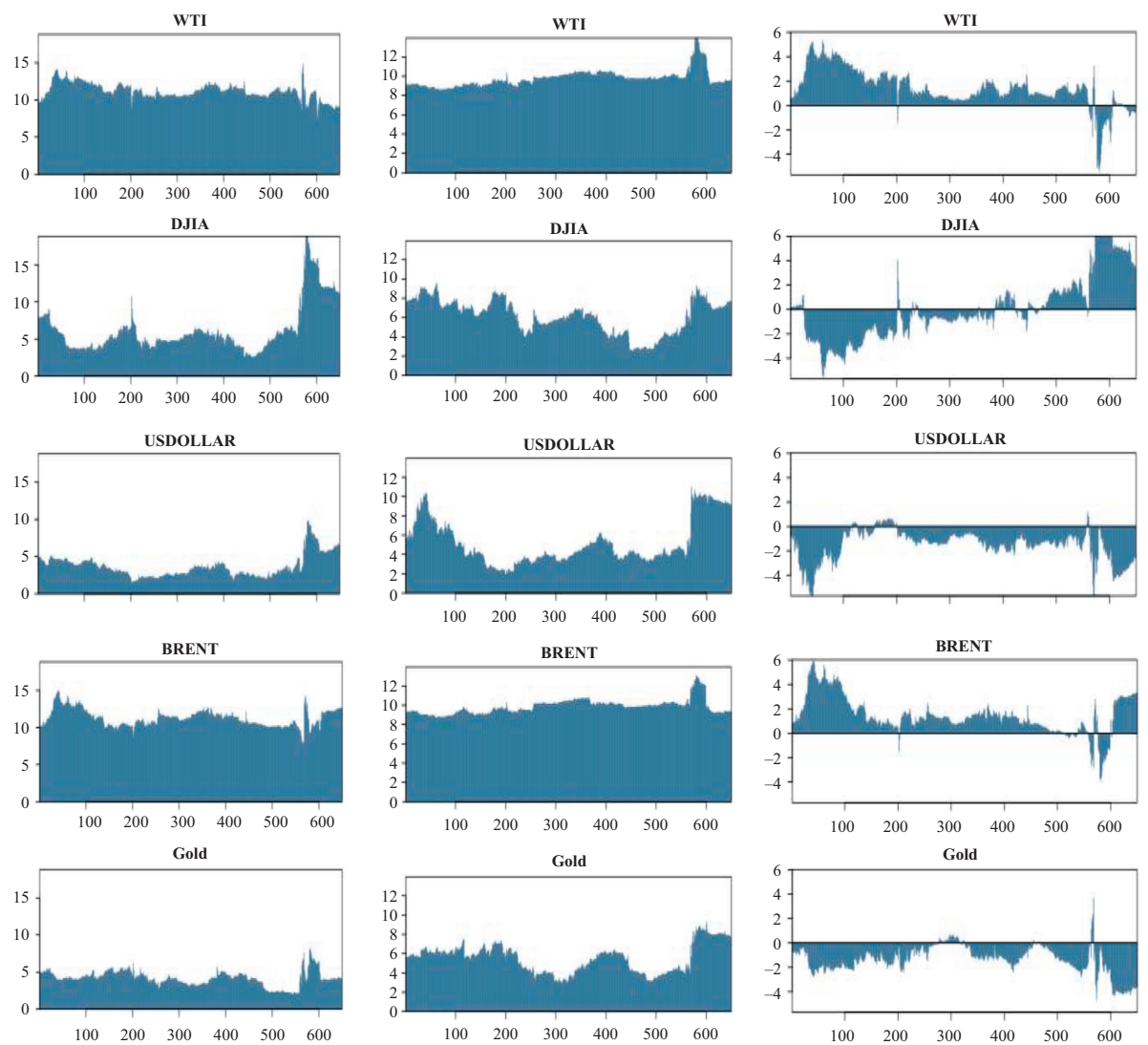

Figure A2.

Dynamic total connectedness

Figure A3.

Volatility spillover FROM, TO and Net 


\section{EJMBE 30,3}

\section{About the author}

Dr Imlak Shaikh is an Assistant Professor of Accounting and Finance at MDI Gurgaon. Previously, he served as an Assistant Professor at the Birla Institute of Technology and Science, BITS Pilani. Shaikh has also taught at IIM Rohtak as an Adjunct Faculty in FPM program. Shaikh received his postgraduation degree in commerce from the Veer Narmad South Gujarat University Surat; his $\mathrm{PhD}$ from the Indian Institute of Technology Bombay (IIT-Bombay). Shaikh has been awarded with "PhD Thesis Excellence Award" from IIT-Bombay. He has recently published in North American Journal of Economics and Finance, Engineering Economics, Journal of Business Economics and Management, Economic Change and Restructuring, Borsa Istanbul Review, Journal of Economic Studies and so on. Imlak Shaikh can be contacted at: imlak786@gmail.com

For instructions on how to order reprints of this article, please visit our website: www.emeraldgrouppublishing.com/licensing/reprints.htm Or contact us for further details: permissions@emeraldinsight.com 